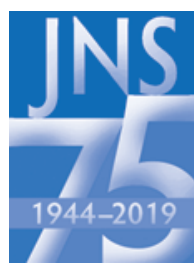

\title{
Lessons learned in the evolution of endoscopic skull base surgery
}

\author{
JNSPG 75th Anniversary Invited Review Article
}

\begin{abstract}
Theodore H. Schwartz, MD, ${ }^{1-3}$ Peter F. Morgenstern, MD, ${ }^{1}$ and Vijay K. Anand, MD²
Departments of ${ }^{1}$ Neurological Surgery and ${ }^{2}$ Otorhinolaryngology, NewYork-Presbyterian Hospital/Weill Cornell Medicine, New York; and ${ }^{3}$ Department of Neuroscience, Weill Cornell Medical College, New York, New York
\end{abstract}

OBJECTIVE Endoscopic skull base surgery (ESBS) is a relatively recent addition to the neurosurgical armamentarium. As with many new approaches, there has been significant controversy regarding its value compared with more traditional approaches to ventral skull base pathology. Although early enthusiasm for new approaches that appear less invasive is usually high, these new techniques require rigorous study to ensure that widespread implementation is in the best interest of patients.

METHODS The authors compared surgical results for ESBS with transcranial surgery (TCS) for several different pathologies over two different time periods (prior to 2012 and 2012-2017) to see how results have evolved over time. Pathologies examined were craniopharyngioma, anterior skull base meningioma, esthesioneuroblastoma, chordoma, and chondrosarcoma.

RESULTS ESBS offers clear advantages over TCS for most craniopharyngiomas and chordomas. For well-selected cases of planum sphenoidale and tuberculum sellae meningiomas, ESBS has similar rates of resection with higher rates of visual improvement, and more recent results with lower CSF leaks make the complication rates similar between the two approaches. TCS offers a higher rate of resection with fewer complications for olfactory groove meningiomas. ESBS is preferred for lower-grade esthesioneuroblastomas, but higher-grade tumors often still require a craniofacial approach. There are few data on chondrosarcomas, but early results show that ESBS appears to offer clear advantages for minimizing morbidity with similar rates of resection, as long as surgeons are familiar with more complex inferolateral approaches.

CONCLUSIONS ESBS is maturing into a well-established approach that is clearly in the patients' best interest when applied by experienced surgeons for appropriate pathology. Ongoing critical reevaluation of outcomes is essential for ensuring optimal results.

https://thejns.org/doi/abs/10.3171/2018.10.JNS182154

KEYWORDS endoscopic; endonasal; skull base; craniotomy; craniopharyngioma; meningioma; chordoma; chondrosarcoma; esthesioneuroblastoma; pituitary surgery

\begin{abstract}
"The precondition that is often forgotten in the excitement that comes with change is certainty that the new technology will improve the quality of clinical care for patients. If this precondition is not satisfied, the technology should be abandoned."
\end{abstract}

-Charles B. Wilson

In 2006, in an article in the British Medical Journal,
Charles Wilson outlined the drivers and barriers to the adoption of new surgical technology into neurosurgical practice. ${ }^{86}$ The purpose of the article was to illustrate the risk accompanying the adoption of new technology that may later be found to be ineffective. After reviewing Everett Rogers' well-described S-shaped curve for the diffusion of innovation, which describes innovators, early adaptors, and laggards, he provides examples of both successful and

ABBREVIATIONS CFR = craniofacial resection; ESBS = endoscopic skull base surgery; GTR = gross-total resection; OG = olfactory groove; OS = overall survival; PFS = progression-free survival; PS = planum sphenoidale; TCS = transcranial surgery; TS = tuberculum sellae.

SUBMITTED September 5, 2018. ACCEPTED October 1, 2018.

INCLUDE WHEN CITING DOI: 10.3171/2018.10.JNS182154. 
unsuccessful neurosurgical techniques as cautionary tales of irrational exuberance that can surround the proliferation of new ideas.

Wilson outlines several factors that lead to rapid adoption of new technology: 1) The procedure is compatible with current practice and can be adequately supported in available facilities. 2) Surgeons can observe the procedure being done. 3) The procedure can be offered to patients for a trial period before it is fully adopted. 4) The procedure is a simple modification of an existing procedure or can be easily learned by attending surgeons. 5) The volume of cases presenting to the hospital and the expected demand from patients justify surgeons learning the procedure. 6) The procedure will appeal to patients.

Wilson provides historical examples such as chymopapain for lumbar disc herniation and superficial temporalmiddle temporal artery bypass as examples of treatments quickly adopted and then eventually largely abandoned for the lack of efficacy, in contrast to endovascular therapy for vascular lesions, a treatment that prevailed over the course of time. He then questions the utility of the nearly universal implementation of spinal instrumentation as a strategy that may require more study. However, Wilson ultimately concludes that, despite barriers to adoption, a technology will and should be adopted throughout the field as long as it has been shown to be in the patients' best interest when rigorously compared to existing technology.

Endoscopic skull base surgery (ESBS) has rapidly proliferated throughout the field of neurosurgery. Like other technologies, it has been widely adopted in some countries and institutions and yet has met barriers and skepticism in other locations. The ease of adoption, myriad courses and training opportunities, and appeal to patients as a "minimally invasive approach" assisted its rapid expansion. However, the lack of randomized clinical trials supporting its use raises concerns regarding its true efficacy compared to more traditional approaches. Moreover, as with many other neurosurgical approaches and technologies, ESBS may be preferable to traditional approaches in some circumstances while remaining substandard in others.

The purpose of this article is to provide an overview of the state of ESBS during its evolution. The key organizing principle is that the learning curve during implementation suggests that conclusions cannot be drawn too early in the development of a new technology. Moreover, not all pathologies and locations benefit from ESBS and when that is the case, areas where the results do not appear to be in the patients' best interest may need to be abandoned. We provide an overview of the literature during two different time periods-namely from 2008 to 2012 and from 2012 to 2017-and compare the results based on specific disease processes (P. F. Morgenstern, unpublished data, 2018). Our goal is not only to establish how the field has progressed during its adolescence but also to critically evaluate the published results as they compare with open transcranial surgery (TCS), to determine in what areas ESBS provides an advantage and in what areas the results are less promising. Common themes are the importance of case selection and surgeon experience for ensuring optimal outcome.

\section{Craniopharyngioma}

Craniopharyngiomas are benign tumors originating from the craniopharyngeal duct that present surgical challenges due to their proximity to the hypothalamus, circle of Willis, optic apparatus, and the pituitary gland and stalk. The hypothalamus and stalk are often challenging dissection planes, and attempts to preserve these structures are important in mitigating risk associated with resection. Craniopharyngiomas tend to push the surrounding neurovasculature upward and outward from a central location. Open skull base approaches have traditionally been limited by the need for significant brain retraction and for working through small surgical windows around major vasculature. Whereas gross-total resection (GTR) provides the patient with the highest rate of progressionfree survival (PFS), intentional subtotal resection performed to preserve hypothalamic and/or pituitary function by both ESBS and TCS has become more common, particularly in the pediatric population. ${ }^{14}$ ESBS, however, has been shown to achieve higher rates of hypothalamic preservation regardless of the degree of involvement by tumor. ${ }^{78,88}$

While TCSs for craniopharyngioma resection have been applied for many years, there are ongoing efforts to evaluate and improve these approaches to reduce the rates of significant morbidity. Minimally invasive modifications such as the supraorbital keyhole approach, with or without endoscopic assistance, have been used for lesions extending into the third ventricle and with significant retrochiasmatic components. ${ }^{79}$ However, the supraorbital approach is limited in its ability to visualize under the ipsilateral optic nerve and into the sella as well as high up into the ventricle. Traditional transcranial approaches are still the mainstay for surgeons unfamiliar with ESBS.

ESBS facilitates exposure of the tumor without traversing the critical neurovascular structures and has been shown to be associated with decreased morbidity. The ventral approach minimizes optic nerve and brain retraction while exposing not only sellar tumors but also those with suprasellar, third ventricular, and interpeduncular extension. The traditional microscopic approach is limited by a narrow visualized field and the resulting difficulty obtaining a complete resection. The addition of the endoscope has changed the calculus for approaching these tumors ventrally, because wide exposure is afforded through a minimally invasive corridor. Both endoscopic and microscopic ventral approaches remain limited for the removal of tumors with lateral extension beyond the carotid arteries.

\section{Data Before 2012}

Even prior to 2012, the literature demonstrated favorable rates of GTR (66.9\% ESBS vs $48.3 \%$ TCS, p < 0.003$)$ and fewer complications, including seizure $(0.0 \%$ ESBS vs $8.5 \%$ TCS, $\mathrm{p}<0.001)$ and diabetes insipidus $(27.7 \%$ ESBS vs $54.8 \%$ TCS, $\mathrm{p}<0.003$ ), with better visual outcome (56.2\% ESBS vs 33.1\% TCS improved, $\mathrm{p}<0.003$; $1.7 \%$ ESBS vs $11.3 \%$ TCS deteriorated, $p<0.003$ ) and lower recurrences (18.4\% ESBS vs $28.2 \%$ TCS, not significant) favoring the endoscopic endonasal approach. The CSF leak rate was higher in the endoscopic group (18.4\% 
TABLE 1. Treatment outcome in craniopharyngioma

\begin{tabular}{lccc}
\hline \multicolumn{1}{c}{ Op Type } & GTR & CSF Leak & Visual Improvement \\
\hline TCS & $40.0-89.6 \%$ & $4.0 \%$ & $0.0-47.1 \%$ \\
\hline ESBS & & & \\
\hline Prior to 2012 & $66.9 \%$ & $18.4 \%$ & $56.2 \%$ \\
\hline $2012-2017$ & $46.0-96.0 \%$ & $2.9-23.5 \%$ & $56.2-88.9 \%$ \\
\hline
\end{tabular}

ESBS vs $2.6 \%$ TCS, $\mathrm{p}<0.003$ ), but this did not portend a statistically significant increase in the rate of meningitis (Table 1). ${ }^{43}$

\section{Data From 2012 to 2017}

Recently published studies of ESBS have further supported this route as the treatment of choice for the majority of craniopharyngiomas. ${ }^{84}$ This approach has continued to demonstrate higher rates of GTR (66.9\%-96.0\% ESBS vs 40.0\%-89.6\% TCS), visual improvement $(56.2 \%-88.9 \%$ ESBS vs $0.0 \%-47.1 \%$ TCS), fewer neurological and other complications (4.0\%-20.0\% ESBS vs $33.0 \%-80.0 \%$ TCS), and shorter length of hospitalization (4 days ESBS vs 10 days TCS). ${ }^{3,12,38,63,91,97}$ CSF leak rates with ESBS in more recent large series in which nasal septal flap closure was used are now $2.9 \%-5.2 \%$, much lower than in previous reports. ${ }^{12,67}$ Furthermore, improving exposure techniques and cadaveric studies have expanded the utility of this approach even for large and difficult tumors in adults and children. ${ }^{1,16}$ Recent studies have demonstrated that large tumors, those in difficult locations with limited surgical corridors, and even recurrent tumors can be safely and effectively resected using ESBS., ${ }^{72,16,21,40}$ Furthermore, it has been shown that a narrow surgical window between the pituitary gland and optic chiasm does not preclude a ventral approach ${ }^{64}$ Recurrent tumors present significant challenges when treated via either approach, but with ESBS it appears that the extent of resection (87.0\%) and visual outcomes (76.5\% improvement) remain similar, and major complication rates are comparable to first-time rates $(3.6 \%$ first time vs $0.0 \%$ recurrent), but with a higher rate of new postoperative diabetes insipidus for reoperations $(47.0 \%$ first time vs $80.0 \%$ recurrent). ${ }^{21}$ Prior radiation, however, continues to make further surgery more complicated, regardless of the approach..$^{90}$

One criticism of comparisons between ESBS and TCS is that smaller tumors may be chosen for ESBS, whereas larger and more complex tumors are chosen for TCS. This would bias the results in favor of ESBS. To address this criticism, Moussazadeh et al. published a comparison study in which all tumors were viewed by 3 surgeons blinded to the approach chosen, to ensure that all tumors could be removed equally well with either approach. ${ }^{63}$ If one approach was favored, then the case was eliminated. In this series, ESBS had a higher rate of GTR $(90.0 \%$ vs $40.0 \% ; \mathrm{p}=0.009)$, a higher rate of visual improvement $(63.0 \%$ vs $0.0 \%$; $\mathrm{p}<0.05)$, less postoperative FLAIR signal in the frontal lobe $\left(0.16 \pm 4.6 \mathrm{~cm}^{3}\right.$ vs $14.4 \pm 14.0 \mathrm{~cm}^{3}$; $\mathrm{p}<0.001)$, and fewer complications $(20.0 \%$ vs $80.0 \%$; $\mathrm{p}<$ 0.001) compared with TCS. ${ }^{63}$

In children, for whom minimally invasive approach- es are particularly attractive and large tumors are often found, recent series have shown utility and efficacy with ESBS, with high rates of visual improvement and infrequent major complications as well as lower rates of hypothalamic obesity in some, but not all, series., ${ }^{1,253}$ Today the majority of children with craniopharyngioma are treated with a transcranial approach, but this trend may be changing as pediatric specialists partner with skull base colleagues with endoscopic experience and it becomes clear that this approach is at least comparable if not more effective and safer. ${ }^{1,6}$

TCS approaches remain important for tumors with significant lateral extension beyond the carotid arteries and for those that are primarily intraventricular or that extend superior to the foramina of Monro. However, for most midline tumors ESBS provides the most direct approach with the highest rates of GTR and visual improvement, and the least brain retraction and other neurological complications (Table 1).

\section{Anterior Skull Base Meningioma}

Meningiomas of the anterior cranial base amenable to ESBS can be divided into olfactory groove $(\mathrm{OG})$, planum sphenoidale (PS), and tuberculum sellae (TS) origins. Controversy remains, however, as to the optimal surgical approach for these lesions. Importantly, skull base meningiomas are subject to limitations that may prevent the wide marginal resections afforded to convexity meningiomas. Furthermore, recent literature has suggested that the Simpson grading scale traditionally used for extent of resection may be less relevant for skull base meningiomas than for convexity lesions, particularly because adjuvant radiotherapy for residual or recurrent tumor has been shown to be effective. ${ }^{76}$

As is the case for other anterior cranial base pathology, PS/TS and OG meningiomas present important challenges by either TCS or ESBS. Open approaches often require the surgeon to work through narrow neurovascular windows between the carotid, middle cerebral, and anterior cerebral arteries and optic apparatus. Residual tumor is often left in the medial optic canal unless this area is opened widely. However, a wider opening may increase the risk of CSF leakage, and the attachment of the tumor and hyperostosis are often not completely removed because of this fear. ESBS results in a direct route into the tumor but has limited lateral vision, and the dural tail can easily be left behind. Although the skull base attachment is removed during the approach, this creates a need for repair of a skull base defect to prevent postoperative CSF leaks, of which the rate can be quite high depending on the method of closure and the experience of the surgeon. ${ }^{39,65}$

Modifications of TCS have been described in recent years, including minimally invasive keyhole approaches and various modifications of the pterional craniotomy, subfrontal, and anterior interhemispheric approaches. . $^{17,23,56,80}$ The supraorbital approach in particular has been described extensively, with endoscopic assistance being applied with the goal of increasing GTR rates and reducing the need for significant manipulation of the optic apparatus. ${ }^{87}$ One study noted a higher rate of GTR $(93.3 \%)$ and visual improvement (90.9\%) than in previously published 
TABLE 2. Treatment outcome in PS and TS meningioma

\begin{tabular}{lccc}
\hline \multicolumn{1}{c}{ Op Type } & GTR & CSF Leak & Visual Improvement \\
\hline TCS & $85.8 \%$ & $5.8 \%$ & $58.4-60.7 \%$ \\
\hline ESBS & & & \\
\hline Prior to 2012 & $74.7 \%$ & $21.3 \%$ & $69.1 \%$ \\
\hline $2012-2017$ & $83.0-91.7 \%$ & $0.0-20 \%$ & $75.0-88.9 \%$ \\
\hline
\end{tabular}

literature.$^{56} \mathrm{TCS}$ has also been noted to be more likely to preserve olfaction, particularly for PS/OG lesions that necessitate disruption of the olfactory mucosa by ESBS..$^{29}$

Because these tumors are typically confined to the midline, they are well suited to an endonasal approach. The points to consider in approach selection for anterior skull base meningiomas differ based on location. ${ }^{66}$ For PS/TS meningiomas, proximity to the optic nerves makes visual outcome a priority. These tumors often invade the medial optic canal and thus require an approach that exposes the medial canal. Although this area was originally thought to be difficult to reach endonasally, more recent reports have shown that the medial optic canal can be easily approached using ESBS. ${ }^{5,49}$ Moreover, when these tumors extend laterally to the anterior clinoids or internal carotid artery they become impossible to remove completely through an endonasal approach, which makes careful case selection critical for successful outcome. ${ }^{39,65,66}$ On the other hand, OG meningiomas lie in close approximation with the olfactory nerves, and so when olfaction is intact preoperatively, their preservation is critical to maintain it. These tumors can also extend laterally over the orbits and beyond the reach of the endonasal approach. For these reasons, cases with preserved olfaction or lateral extent may not be suitable for ESBS. ${ }^{66}$

\section{Data Before 2012}

\section{PS/TS Meningiomas}

Prior to 2012, GTR was higher when using TCS compared with ESBS (84.1\% vs 74.7\%; $p=0.041)$. Moreover, the CSF leak rate with ESBS was still quite high $(21.3 \%$ vs $4.3 \% ; \mathrm{p}<0.001)$. However, there was a trend toward more frequent improved visual outcome using ESBS (69.1\% vs $58.7 \% ; \mathrm{p}=0.130$ ) (Table 2). At this point in time, the technique was still developing and the key aspects of the surgery that were required to determine if this approach would lead to improved outcomes were a reduction in CSF leaks, the ability to open the medial optic canal, and the knowledge of the limitations of the approach (i.e., to avoid trying to operate on tumors with lateral extension that cannot be removed). Although the presence of a "cortical cuff" was thought to be important to avoid vascular injury, this was later found not to be a contraindication to surgery, assuming the surgeon was adept at endonasal microscopic bimanual surgery. ${ }^{20,39,65}$

\section{OG Meningiomas}

For OG meningiomas, the GTR rate was also higher for TCS compared with ESBS $(92.8 \%$ vs $63.2 \%$; p < $0.001)$ and the CSF leak disparity was even larger (6.0\% vs $31.6 \%$; $p<0.001) .{ }^{44}$ Since the rate of loss of olfaction was $100.0 \%$ with ESBS, this led to the question of whether
TABLE 3. Treatment outcome in OG meningioma

\begin{tabular}{lccc}
\hline \multicolumn{1}{c}{ Op Type } & GTR & CSF Leak & Visual Improvement \\
\hline TCS & $92.8 \%$ & $6.0 \%$ & $50.6 \%$ \\
\hline ESBS & & & \\
\hline Prior to 2012 & $63.2 \%$ & $31.6 \%$ & $20.0 \%$ \\
\hline $2012-2017$ & $70.9 \%$ & $25.1 \%$ & $64.5 \%$ \\
\hline
\end{tabular}

ESBS should be used at all for OG meningiomas and if so, how to select the appropriate cases (Table 3).

\section{Data From 2012 to 2017}

\section{PS/TS Meningiomas}

ESBS for anterior skull base meningiomas has been studied more extensively in recent years. For patients with PS/TS meningiomas, as the numbers have increased, ESBS has been shown to lead to higher rates of visual improvement compared with TCS (75.0\% vs 58.4\%) ${ }^{18}$ Moreover, case selection has improved, which has resulted in higher rates of GTR for ESBS and fewer complications. To avoid selection bias, comparisons between the two approaches must be done for tumors with similar anatomy, because results could be biased against either approach, depending on patient selection. For example, early comparisons tended to include a higher proportion of small tumors in the ESBS group. A recent study, however, showed that for matched tumors that appear to be amenable to either TCS or ESBS, GTR rates are comparable but ESBS has lower rates of visual deterioration ( $0.0 \%$ vs $44.0 \%)$ and higher rates of visual improvement (93.0\% vs 56.0\%). Anosmia and CSF leak remain more common with ESBS, but with rates of CSF leakage far lower than in the early series. ${ }^{8}$ A more recent series of ESBS for PS/TS meningiomas has shown that GTR rates can be as high as $91.7 \%$, with CSF leaks as low as $0.0 \%$ and with visual improvement in $88.9 \%$ (Table 2). ${ }^{65}$ Even vascular encasement or the lack of a cortical cuff can be overcome with ESBS, although with careful attention to vascular adherence or invasion seen on preoperative imaging. ${ }^{20,39,47}$

\section{OG Meningiomas}

A recently published systematic review of OG meningiomas demonstrated that in contrast to PS/TS meningiomas, the results of ESBS for OG meningiomas have shown little improvement over time. Although visual outcomes were better in the ESBS group ( $80.7 \%$ vs $12.83 \%$; $\mathrm{p}<0.001)$, GTR rates were higher in the TCS group $(90.99 \%$ vs $70.29 \%$; $p<0.0001)$ and CSF leak rates were higher in the ESBS group (25.74\% vs $6.30 \%$; $\mathrm{p}<0.0001)$. Other individual series lend support to these conclusions in large part, and continue to report high rates of CSF leakage for this particular subset of tumors, without significant improvement over the last 5-10 years (Table 3) ${ }^{47}$ Furthermore, some have suggested that although ESBS is becoming a preferred approach for TS/PS meningiomas, OG meningiomas are more effectively removed by other minimally invasive means, such as the supraorbital keyhole approach with endoscopic assistance or even more standard transcranial approaches, such as the bifrontal or pterional. ${ }^{9}$ Another important limitation to ESBS for 
TABLE 4. Treatment outcome in esthesioneuroblastoma

\begin{tabular}{ccc}
\hline Op Type & GTR & CSF Leak \\
\hline TCS & $85.2 \%$ & $6.0-10.3 \%$ \\
\hline ESBS & & \\
\hline Prior to 2012 & $98.1 \%$ & $7.2 \%$ \\
\hline 2012-2017 & $79.2-95.5 \%$ & $0.0-12.7 \%$ \\
\hline
\end{tabular}

OG meningiomas is that the loss of olfaction is $100.0 \%$, whereas with TCS, olfaction can be preserved in 60.0.\% of patients who have preserved olfaction preoperatively. ${ }^{66}$

\section{Esthesioneuroblastoma}

Esthesioneuroblastoma, or olfactory neuroblastoma, is a rare sinonasal malignancy that, in later stages, can invade the anterior skull base and brain. It is a curable malignancy in early stages, with margin-negative GTR as the surgeon's primary objective. ${ }^{42}$ Adjuvant radiotherapy with or without chemotherapy is common, depending on the extent of disease. Traditional craniofacial resection (CFR) is the longstanding standard approach to managing these tumors. Until recently it represented the only viable route by which a GTR could be achieved. Attempts at more minimally invasive approaches have included lateral rhinotomy or combined open and endonasal (cranionasal) approaches. These have been incorporated into the management scheme at some institutions, and now purely endonasal resections are being evaluated for efficacy in select cases.

\section{Data Before 2012}

A meta-analysis published in 2013 including early literature of ESBS compared with CFR and cranionasal resection demonstrated that an ESBS achieved a high rate of GTR (98.1\% vs $85.2 \%$ ). PFS was also lower with ESBS (8.0\% vs $22.1 \%$ ). However, it is important to recognize that there was also a significant difference in the frequency of higher Kadish stage (C or D) in the CFR group compared to the endonasal group, probably biasing the GTR rate and long-term outcomes in favor of the endonasal group. Major complications including meningitis, CSF leaks, and infection were more common in the CFR group (Table 4). ${ }^{42}$

\section{Data From 2012 to 2017}

The CFR approach continues to be accompanied by a relatively high rate of complications, as high as $52.9 \%$ in a recent meta-analysis. ${ }^{26}$ Individual series have noted wound healing issues in $14.6 \%-36.4 \%$ of cases, infections in $18.2 \%$, neurological complications in $19.2 \%$, and mortality of approximately $1.0 \%$. Current series of open CFR are dominated by later-stage disease, Kadish $\mathrm{C}$ and greater, which may contribute to some degree to the elevated complication rate as well as 5-year overall survival (OS) rates of 59.4\%-95.0\%.32,68,71 For those reporting on early-stage disease treated with either CFR or lateral rhinotomy the results are (as expected) better: $100.0 \%$ survival at 10 years with a margin-negative resection. ${ }^{46}$ Less invasive open cranial approaches, such as the supraciliary approach or other endoscope-assisted craniotomies, have been used for certain tumors, avoiding extensive CFR exposure but reaching tumors that are difficult to access via the endonasal approach. However, these have not been systematically explored in great depth for long-term outcomes and complication rates..$^{10,81}$

Purely endoscopic resections continue to proliferate, demonstrating high 5-year OS (82.0\%-97.0\%) and GTR rates in series that typically comprise a large percentage of Kadish A and B disease (Table 4). ${ }^{19,24,35,89}$ GTR rates reported in more recent studies are actually lower in some cases than in prior series, although this may be in part due to attempts to treat higher-stage disease with ESBS in recent years. Some have also described the potential benefit of olfactory preservation for early-stage disease while still achieving negative margins. ${ }^{85,89}$

Patients undergoing ESBS with later-stage disease according to either Dulguerov or Kadish criteria had a 5-year OS rate of $46.2 \% .{ }^{94}$ Recent technical reports describe margin-negative resection with ESBS for Kadish C disease, which over time should translate into a survival benefit..$^{58}$ One single-institution study demonstrated a higher margin-negative resection rate for ESBS over CFR (84.2\% vs $53.1 \%$ ) for Kadish C disease, although this result needs to be replicated in larger studies..$^{30}$

Lower morbidity continues to be the norm for ESBS when compared to open approaches for this tumor type..$^{19}$ ESBS is associated with decreased blood loss, operating time, length of hospital stay, and complication rates, as well as improved cosmetic outcome. ${ }^{60,77}$ Studies of open versus endonasal approaches for pooled groups of sinonasal malignancies, including esthesioneuroblastoma, have shown comparable GTR rates between the two. ${ }^{26,30}$

The current practice appears to favor ESBS or combined approaches for early-stage, endoscopically accessible disease. This approach has been shown to achieve comparable rates of disease control with lower morbidity than a traditional CFR..$^{19,30,33}$ For later-stage, more invasive disease, some can be resected successfully endoscopically, but CFR should still be considered to achieve a maximal safe resection, particularly for difficult lesions. ${ }^{68}$ Ongoing advances in endoscopic technique may be shifting that balance. Good sinonasal outcome test (SNOT-20) scores and low complication rates make ESBS an appealing option when feasible for this malignancy. ${ }^{26,55}$

\section{Chordoma}

Skull base chordomas are rare tumors, derived from remnants of the primitive notochord, with incidence in the vicinity of 0.08 per $100,000 .{ }^{57}$ Symptomatic presentation is variable and dependent on tumor location. Prognosis is influenced by older age, partial resection, preoperative visual deficits, enhancement on MRI, and tumor grade. ${ }^{52}$ Adjuvant radiotherapy has been shown to extend PFS and OS, whereas chemotherapy does not play a role at this time. ${ }^{96}$ Resection remains the mainstay of therapy for chordoma, but is limited by the lesion's relationships to critical neurovascular structures. ${ }^{11}$ Given their site of origin, chordomas lend themselves to ESBS because they arise in an extradural ventral location and tend to push neurovascular structures away from the operative corridor. 
TABLE 5. Treatment outcome in chordoma

\begin{tabular}{lccc}
\hline \multicolumn{1}{c}{ Op Type } & GTR & CSF Leak & Neuro Deficit \\
\hline TCS & $48.0 \%$ & $10.7 \%$ & $24.0-35.3 \%$ \\
\hline ESBS & & & \\
\hline Prior to 2012 & $61.0 \%$ & $5.0 \%$ & $1.3 \%$ \\
\hline $2012-2017$ & $28.0-66.7 \%$ & $0.0-16.0 \%$ & $3.8 \%$ \\
\hline
\end{tabular}

Neuro $=$ neurological

However, these tumors are often locally invasive, making complete resection difficult regardless of approach.

Although en bloc resection has traditionally been thought to offer the best chance of long-term recurrencefree survival, intralesional resection has been shown to offer similar disease control and potentially improved functional outcomes, encouraging the development of less invasive approaches. ${ }^{36,83}$ Slow growth results in bony remodeling and drastic deformation of surrounding structures, often without significant preoperative deficits.

Oncological considerations are critical in the management of these tumors. Five-year OS is approximately $67.5 \%$ in recent series. Radiation therapy is a standard adjuvant treatment for these patients after surgery ${ }^{45}$ These anatomical and oncological considerations are critical in considering ESBS and open approaches. ESBS presents a minimally invasive direct corridor into these midline clival tumors. ${ }^{60}$

\section{Data Before 2012}

Early data demonstrated higher rates of GTR for ESBS compared with TCS $(61.0 \%$ vs $48.1 \%)$, fewer postoperative deficits ( $1.3 \%$ vs $24.2 \%)$, lower recurrence rates $(16.9 \%$ vs $40.0 \%$ ), and fewer complications, although with shorter follow-up in the ESBS group given its more recent introduction..$^{45} \mathrm{~A}$ criticism of these data is that cases selected for ESBS were more likely to be smaller midline tumors with limited lateral extension, which would be a bias toward better results in these cases.

\section{Data From 2012 to 2017}

Over time more studies have been published on ESBS, reporting GTR rates of $28.0 \%-66.7 \%,{ }^{41,69,93,95}$ still mostly exceeding those of open approaches..$^{50}$ The wide range of GTR rates perhaps reflects the heterogeneity of size and anatomy of these tumors, as well as the widely variable expertise of surgeons using these more novel techniques. Low rates of neurological compromise are typical (3.8\%), and lesions located in the superior and middle clivus in the midline tend to be more amenable to complete resection. ${ }^{28,37,95}$ Open approaches, even in recent series, have demonstrated neurological complication rates as high as $35.3 \% .^{83}$ The open approaches remain essential, however, for lesions with significant lateral or inferior extension. ${ }^{74}$ The efficacy and safety of ESBS has also been demonstrated in the pediatric population. ${ }^{82}$ Complication rates in this population, with the exception of CSF leaks, remain lower than for open approaches. ${ }^{50}$ Although many of these tumors are extradural and thus the rates of CSF leakage are low, for those that have a large intradural extension,
TABLE 6. Treatment outcome in chondrosarcoma

\begin{tabular}{lccc}
\hline \multicolumn{1}{c}{ Op Type } & GTR & CSF Leak & Neuro Deficit \\
\hline TCS & $50.0-100.0 \%$ & $9.0-13.0 \%$ & $24.0-85.0 \%$ \\
\hline ESBS & & & \\
\hline Prior to 2012 & NA & NA & NA \\
\hline $2012-2017$ & $40.0-79.0 \%$ & $5.0-13.0 \%$ & $0.0-20.0 \%$ \\
\hline
\end{tabular}

$\mathrm{NA}=$ not available.

CSF leaks are higher but comparable to TCS. Published CSF leak rates in several series are comparable between TCS and ESBS (Table 5). ${ }^{75}$ Recent ESBS data report CSF rates of $0.0 \%-16.3 \% .41,54$

Overall, ESBS for chordomas has become more prevalent and multiple large studies have evaluated the safety and efficacy of this approach. Compared to open surgery, ESBS has been shown to lead more frequently to a higher percentage of GTR (28.0\%-66.7\% vs $48.0 \%)$, lower neurological morbidity (3.8\% vs $24.0 \%-35.3 \%$ ), lower incidence of meningitis $(0.0 \%$ vs $0.0 \%-13.0 \%)$, and decreased perioperative mortality $(0.0 \%$ vs $0.0 \%-24.0 \%))^{15,27,28,45,48}$ The data on recurrence rates are more equivocal and require longer-term follow-up. ${ }^{27,45,48}$

\section{Chondrosarcoma}

Similarly to chordoma, skull base chondrosarcoma is a rare tumor. It is different in that it arises from skull base synchondroses and has a more indolent course in most cases. ${ }^{4}$ Although adjuvant radiotherapy is effective for more aggressive (WHO grade II/III) or recurrent tumors, GTR remains the optimal treatment regardless of grade when achievable with minimal morbidity. ${ }^{51,73}$ Chondrosarcomas often arise from the petroclival synchondrosis, and ESBS provides a more direct route to this extradural location than TCS. Neurovascular structures are pushed superiorly and laterally, and TCS is more likely to traverse cranial nerves than is ESBS. Data comparing ESBS to TCS for chondrosarcoma are sparse, and primarily limited to small reports due to the disease's uncommon presentation. Variable tumor morphology also creates challenges for comparison studies. Open approaches have resulted in high success rates in individual series, primarily by pterional and retrosigmoid craniotomy. ${ }^{72}$ Early case reports and series have shown that ESBS for chondrosarcomas of the skull base is feasible with minimal morbidity. ${ }^{25,92}$

The development of the transmaxillary, transpterygoidal approach has increased the utility of ESBS for chondrosarcomas. ${ }^{34,62}$ Bolstering the utility of this approach are data demonstrating that intralesional resection is an effective strategy that achieves comparable oncological control to en bloc resection. ${ }^{13}$ Even tumors with extension into the cerebellopontine angle have been shown to be reachable with ESBS. ${ }^{59}$ Recent studies of ESBS for chondrosarcoma have shown GTR rates of $66.7 \%-80.0 \%$, and as high as $93.0 \%$ control at 5 years. Transcranial approaches result in reported GTR rates of $50.0 \%-100.0 \%$ (Table 6). ${ }^{22,31,41,62,70}$ In some large multicompartmental tumors, combinations of ESBS and TCS are often needed to achieve a maximal safe resection. ${ }^{70}$ 


\section{Conclusions}

Development of new surgical approaches for intracranial pathology requires comparisons to existing standard approaches. The evolution of a new approach associated with the surgeon's learning curve, development of new equipment, and new techniques contributes to its efficacy and safety. ESBS has increasingly gained acceptance as a minimally invasive, effective option for a range of skull base pathologies, and comparisons of TCS and ESBS continue to be published in which the differences between these two are described. We have demonstrated several important points for the surgeon to consider in choosing an approach based on a review of the recent literature on ESBS for craniopharyngiomas, anterior skull base meningiomas, esthesioneuroblastomas, chordomas, and chondrosarcomas. We demonstrate where these approaches can be implemented in the patients' best interest and where further data or technical developments are required. For certain pathologies and locations ESBS offers clear advantages, whereas for others the results are equivalent or even inferior. In these situations, if improvements are not forthcoming ESBS may not be the optimal approach.

\section{References}

1. Alalade AF, Ogando-Rivas E, Boatey J, Souweidane MM, Anand VK, Greenfield JP, et al: Suprasellar and recurrent pediatric craniopharyngiomas: expanding indications for the extended endoscopic transsphenoidal approach. J Neurosurg Pediatr 21:72-80, 2018

2. Ali ZS, Lang SS, Kamat AR, Adappa ND, Palmer JN, Storm $\mathrm{PB}$, et al: Suprasellar pediatric craniopharyngioma resection via endonasal endoscopic approach. Childs Nerv Syst 29:2065-2070, 2013

3. Alli S, Isik S, Rutka JT: Microsurgical removal of craniopharyngioma: endoscopic and transcranial techniques for complication avoidance. J Neurooncol 130:299-307, 2016

4. Almefty K, Pravdenkova S, Colli BO, Al-Mefty O, Gokden M: Chordoma and chondrosarcoma: similar, but quite different, skull base tumors. Cancer 110:2457-2467, 2007

5. Attia M, Kandasamy J, Jakimovski D, Bedrosian J, Alimi M, Lee DLY, et al: The importance and timing of optic canal exploration and decompression during endoscopic endonasal resection of tuberculum sella and planum sphenoidale meningiomas. Neurosurgery 71 (1 Suppl Operative):58-67, 2012

6. Bakhsheshian J, Jin DL, Chang KE, Strickland BA, Donoho DA, Cen S, et al: Risk factors associated with the surgical management of craniopharyngiomas in pediatric patients: analysis of 1961 patients from a national registry database. Neurosurg Focus 41(6):E8, 2016

7. Bal E, Öge K, Berker M: Endoscopic endonasal transsphenoidal surgery, a reliable method for treating primary and recurrent/residual craniopharyngiomas: nine years of experience. World Neurosurg 94:375-385, 2016

8. Bander ED, Singh H, Ogilvie CB, Cusic RC, Pisapia DJ, Tsiouris AJ, et al: Endoscopic endonasal versus transcranial approach to tuberculum sellae and planum sphenoidale meningiomas in a similar cohort of patients. J Neurosurg 128:40-48, 2018

9. Banu MA, Mehta A, Ottenhausen M, Fraser JF, Patel KS, Szentirmai O, et al: Endoscope-assisted endonasal versus supraorbital keyhole resection of olfactory groove meningiomas: comparison and combination of 2 minimally invasive approaches. J Neurosurg 124:605-620, 2016

10. Barzo P, Zador Z, Bodosi M, Bella Z, Jambor D, Fulop B, et al: Combined minimally invasive supraciliary and transfacial approach for large tumors with skull base and sinonasal involvement. World Neurosurg 109:1-9, 2018

11. Brito da Silva H, Straus D, Barber JK, Rostomily RC, Ferreira M Jr, Sekhar LN: Cranial chordoma: a new preoperative grading system. Neurosurgery 83:403-415, 2018

12. Cavallo LM, Frank G, Cappabianca P, Solari D, Mazzatenta D, Villa A, et al: The endoscopic endonasal approach for the management of craniopharyngiomas: a series of 103 patients. J Neurosurg 121:100-113, 2014

13. Chen X, Yu LJ, Peng HM, Jiang C, Ye CH, Zhu SB, et al: Is intralesional resection suitable for central grade 1 chondrosarcoma: a systematic review and updated meta-analysis. Eur J Surg Oncol 43:1718-1726, 2017

14. Cheng J, Fan Y, Cen B: Effect of preserving the pituitary stalk during resection of craniopharyngioma in children on the diabetes insipidus and relapse rates and long-term outcomes. J Craniofac Surg 28:e591-e595, 2017

15. Chibbaro S, Cornelius JF, Froelich S, Tigan L, Kehrli P, Debry $\mathrm{C}$, et al: Endoscopic endonasal approach in the management of skull base chordomas-clinical experience on a large series, technique, outcome, and pitfalls. Neurosurg Rev 37:217-225, 2014

16. Conger AR, Lucas J, Zada G, Schwartz TH, Cohen-Gadol AA: Endoscopic extended transsphenoidal resection of craniopharyngiomas: nuances of neurosurgical technique. Neurosurg Focus 37(4):E10, 2014

17. Curey S, Derrey S, Hannequin P, Hannequin D, Fréger P, Muraine M, et al: Validation of the superior interhemispheric approach for tuberculum sellae meningioma: clinical article. J Neurosurg 117:1013-1021, 2012

18. de Divitiis E, Esposito F, Cappabianca P, Cavallo LM, de Divitiis O: Tuberculum sellae meningiomas: high route or low route? A series of 51 consecutive cases. Neurosurgery 62:556-563, 2008

19. de Gabory L, Verillaud B, Rumeau C, Herman P, Jankowski R, Michel J, et al: Multicenter assessment of exclusive endoscopic endonasal approach for the treatment of 53 olfactory neuroblastomas. Head Neck 40:1000-1007, 2018

20. Dhandapani S, Negm HM, Cohen S, Anand VK, Schwartz TH: Endonasal endoscopic transsphenoidal resection of tuberculum sella meningioma with anterior cerebral artery encasement. Cureus 7:e311, 2015

21. Dhandapani S, Singh H, Negm HM, Cohen S, Souweidane MM, Greenfield JP, et al: Endonasal endoscopic reoperation for residual or recurrent craniopharyngiomas. J Neurosurg 126:418-430, 2017

22. Ditzel Filho LF, Prevedello DM, Dolci RL, Jamshidi AO, Kerr EE, Campbell R, et al: The endoscopic endonasal approach for removal of petroclival chondrosarcomas. Neurosurg Clin N Am 26:453-462, 2015

23. Dogan I, Ucer M, Başkaya MK: Microsurgical resection of tuberculum sellae meningioma via pterional craniotomy with extradural anterior clinoidectomy and optic unroofing. J Neurol Surg B Skull Base 79:S218, 2018

24. Feng L, Fang J, Zhang L, Li H, Zhou B, Chen X, et al: Endoscopic endonasal resection of esthesioneuroblastoma: a single center experience of 24 patients. Clin Neurol Neurosurg 138:94-98, 2015

25. Frank G, Sciarretta V, Calbucci F, Farneti G, Mazzatenta D, Pasquini E: The endoscopic transnasal transsphenoidal approach for the treatment of cranial base chordomas and chondrosarcomas. Neurosurgery 59 (1 Suppl 1):ONS50-ONS57, 2006

26. Fu TS, Monteiro E, Muhanna N, Goldstein DP, de Almeida JR: Comparison of outcomes for open versus endoscopic approaches for olfactory neuroblastoma: a systematic review and individual participant data meta-analysis. Head Neck 38 (Suppl 1):E2306-E2316, 2016 
27. Graffeo CS, Dietrich AR, Grobelny B, Zhang M, Goldberg JD, Golfinos JG, et al: A panoramic view of the skull base: systematic review of open and endoscopic endonasal approaches to four tumors. Pituitary 17:349-356, 2014

28. Gui S, Zong X, Wang X, Li C, Zhao P, Cao L, et al: Classification and surgical approaches for transnasal endoscopic skull base chordoma resection: a 6-year experience with 161 cases. Neurosurg Rev 39:321-333, 2016

29. Hannequin P, Paviot A, Chaussy O, Gilard V, Cébula H, Marie JP, et al: Olfaction preservation after removal of large tuberculum sellae meningiomas via a superior interhemispheric approach. A quantitative and qualitative study. Neurochirurgie 61:318-323, 2015

30. Harvey RJ, Nalavenkata S, Sacks R, Adappa ND, Palmer JN, Purkey MT, et al: Survival outcomes for stage-matched endoscopic and open resection of olfactory neuroblastoma. Head Neck 39:2425-2432, 2017

31. Hasegawa H, Shin M, Kondo K, Hanakita S, Mukasa A, Kin $\mathrm{T}$, et al: Role of endoscopic transnasal surgery for skull base chondrosarcoma: a retrospective analysis of 19 cases at a single institution. J Neurosurg 128:1438-1447, 2018

32. Herr MW, Sethi RKV, Meier JC, Chambers KJ, Remenschneider A, Chan A, et al: Esthesioneuroblastoma: an update on the Massachusetts Eye and Ear Infirmary and Massachusetts General Hospital experience with craniofacial resection, proton beam radiation, and chemotherapy. J Neurol Surg B Skull Base 75:58-64, 2014

33. Higgins TS, Thorp B, Rawlings BA, Han JK: Outcome results of endoscopic vs craniofacial resection of sinonasal malignancies: a systematic review and pooled-data analysis. Int Forum Allergy Rhinol 1:255-261, 2011

34. Hofstetter CP, Singh A, Anand VK, Kacker A, Schwartz TH: The endoscopic, endonasal, transmaxillary transpterygoid approach to the pterygopalatine fossa, infratemporal fossa, petrous apex, and the Meckel cave. J Neurosurg 113:967-974, 2010

35. Hwang CS, Seo YW, Park SC, Chung HJ, Cho HJ, Yoon JH, et al: Role of surgical treatment for esthesioneuroblastomas: 31-year experience at a single institution. J Craniomaxillofac Surg 45:120-126, 2017

36. Hyun SJ, Kim JW, Kim KJ, Jahng TA, Roh SW, Ra YS, et al: Long-term results following surgical resection of chordomas in the craniocervical junction and the upper cervical spine: review of 12 consecutive cases. Oper Neurosurg (Hagerstown) 14:112-120, 2018

37. Jahangiri A, Chin AT, Wagner JR, Kunwar S, Ames C, Chou $\mathrm{D}$, et al: Factors predicting recurrence after resection of clival chordoma using variable surgical approaches and radiation modalities. Neurosurgery 76:179-186, 2015

38. Jeswani S, Nuño M, Wu A, Bonert V, Carmichael JD, Black $\mathrm{KL}$, et al: Comparative analysis of outcomes following craniotomy and expanded endoscopic endonasal transsphenoidal resection of craniopharyngioma and related tumors: a singleinstitution study. J Neurosurg 124:627-638, 2016

39. Khan OH, Anand VK, Schwartz TH: Endoscopic endonasal resection of skull base meningiomas: the significance of a "cortical cuff" and brain edema compared with careful case selection and surgical experience in predicting morbidity and extent of resection. Neurosurg Focus 37(4):E7, 2014

40. Kim SK, Kim YH, Park CK, Kim DG, Jung HW: Extended endoscopic endonasal approach for recurrent or residual adult craniopharyngiomas. Acta Neurochir (Wien) 156:19171922, 2014

41. Kim YH, Jeon C, Se YB, Hong SD, Seol HJ, Lee JI, et al: Clinical outcomes of an endoscopic transclival and transpetrosal approach for primary skull base malignancies involving the clivus. J Neurosurg 128:1454-1462, 2018

42. Komotar RJ, Starke RM, Raper DMS, Anand VK, Schwartz $\mathrm{TH}$ : Endoscopic endonasal compared with anterior cranio- facial and combined cranionasal resection of esthesioneuroblastomas. World Neurosurg 80:148-159, 2013

43. Komotar RJ, Starke RM, Raper DMS, Anand VK, Schwartz TH: Endoscopic endonasal compared with microscopic transsphenoidal and open transcranial resection of craniopharyngiomas. World Neurosurg 77:329-341, 2012

44. Komotar RJ, Starke RM, Raper DMS, Anand VK, Schwartz TH: Endoscopic endonasal versus open transcranial resection of anterior midline skull base meningiomas. World Neurosurg 77:713-724, 2012

45. Komotar RJ, Starke RM, Raper DMS, Anand VK, Schwartz TH: The endoscope-assisted ventral approach compared with open microscope-assisted surgery for clival chordomas. World Neurosurg 76:318-327, 259-262, 2011

46. König M, Osnes T, Jebsen P, Evensen JF, Meling TR: Olfactory neuroblastoma: a single-center experience. Neurosurg Rev 41:323-331, 2018

47. Koutourousiou M, Fernandez-Miranda JC, Wang EW, Snyderman $\mathrm{CH}$, Gardner PA: Endoscopic endonasal surgery for olfactory groove meningiomas: outcomes and limitations in 50 patients. Neurosurg Focus 37(4):E8, 2014

48. Koutourousiou M, Gardner PA, Tormenti MJ, Henry SL, Stefko ST, Kassam AB, et al: Endoscopic endonasal approach for resection of cranial base chordomas: outcomes and learning curve. Neurosurgery 71:614-625, 2012

49. Kulwin C, Schwartz TH, Cohen-Gadol AA: Endoscopic extended transsphenoidal resection of tuberculum sellae meningiomas: nuances of neurosurgical technique. Neurosurg Focus 35(6):E6, 2013

50. Labidi M, Watanabe K, Bouazza S, Bresson D, Bernat AL, George B, et al: Clivus chordomas: a systematic review and meta-analysis of contemporary surgical management. J Neurosurg Sci 60:476-484, 2016

51. Li D, Weng JC, Zhang GJ, Hao SY, Tang J, Zhang LW, et al: Proposed treatment paradigm for intracranial chondrosarcomas based on multidisciplinary coordination. World Neurosurg 109:e517-e530, 2018

52. Lin E, Scognamiglio T, Zhao Y, Schwartz TH, Phillips CD: Prognostic implications of gadolinium enhancement of skull base chordomas. AJNR Am J Neuroradiol 39:1509-1514, 2018

53. Lin Y, Hansen D, Sayama CM, Pan IW, Lam S: Transfrontal and transsphenoidal approaches to pediatric craniopharyngioma: a national perspective. Pediatr Neurosurg 52:155-160, 2017

54. Mangussi-Gomes J, Beer-Furlan A, Balsalobre L, Vellutini EAS, Stamm AC: Endoscopic endonasal management of skull base chordomas: surgical technique, nuances, and pitfalls. Otolaryngol Clin North Am 49:167-182, 2016

55. Manthuruthil C, Lewis J, McLean C, Batra PS, Barnett SL: Endoscopic endonasal management of olfactory neuroblastoma: a retrospective analysis of 10 patients with quality-of-life measures. World Neurosurg 90:1-5, 2016

56. Marx S, Clemens S, Schroeder HWS: The value of endoscope assistance during transcranial surgery for tuberculum sellae meningiomas. J Neurosurg 128:32-39, 2018

57. McMaster ML, Goldstein AM, Bromley CM, Ishibe N, Parry DM: Chordoma: incidence and survival patterns in the United States, 1973-1995. Cancer Causes Control 12:1-11, 2001

58. Mehta GU, Hanna EY, DeMonte F, Raza SM: Endoscopic endonasal resection of sinonasal/anterior skull base malignancy (Kadish C esthesioneuroblastoma). Acta Neurochir (Wien) 160:361-366, 2018

59. Mesquita Filho PM, Ditzel Filho LFS, Prevedello DM, Martinez CAN, Fiore ME, Dolci RLL, et al: Endoscopic endonasal surgical management of chondrosarcomas with cerebellopontine angle extension. Neurosurg Focus 37(4):E13, 2014

60. Messerer M, Cossu G, Pasche P, Ikonomidis C, Simon C, Pralong E, et al: Extended endoscopic endonasal approach to 
clival and paraclival tumors: indications and limits. Neurochirurgie 62:136-145, 2016

61. Mohindra S, Dhingra S, Mohindra S, Kumar N, Gupta B: Esthesioneuroblastoma: good local control of disease by endoscopic and endoscope assisted approach. Is it possible? Indian J Otolaryngol Head Neck Surg 66:241-247, 201

62. Moussazadeh N, Kulwin C, Anand VK, Ting JY, Gamss C, Iorgulescu JB, et al: Endoscopic endonasal resection of skull base chondrosarcomas: technique and early results. J Neurosurg 122:735-742, 2015

63. Moussazadeh N, Prabhu V, Bander ED, Cusic RC, Tsiouris AJ, Anand VK, et al: Endoscopic endonasal versus open transcranial resection of craniopharyngiomas: a casematched single-institution analysis. Neurosurg Focus 41(6):E7, 2016

64. Omay SB, Almeida JP, Chen YN, Shetty SR, Liang B, Ni $\mathrm{S}$, et al: Is the chiasm-pituitary corridor size important for achieving gross-total resection during endonasal endoscopic resection of craniopharyngiomas? J Neurosurg 129:642647, 2018

65. Ottenhausen M, Banu MA, Placantonakis DG, Tsiouris AJ, Khan OH, Anand VK, et al: Endoscopic endonasal resection of suprasellar meningiomas: the importance of case selection and experience in determining extent of resection, visual improvement, and complications. World Neurosurg 82:442-449, 2014

66. Ottenhausen M, Rumalla K, Alalade AF, Nair P, La Corte E, Younus I, et al: Decision-making algorithm for minimally invasive approaches to anterior skull base meningiomas. Neurosurg Focus 44(4):E7, 2018

67. Park HR, Kshettry VR, Farrell CJ, Lee JM, Kim YH, Won TB, et al: Clinical outcome after extended endoscopic endonasal resection of craniopharyngiomas: two-institution experience. World Neurosurg 103:465-474, 2017

68. Patel SG, Singh B, Stambuk HE, Carlson D, Bridger PG, Cantu G, et al: Craniofacial surgery for esthesioneuroblastoma: report of an international collaborative study. J Neurol Surg B Skull Base 73:208-220, 2012

69. Rahme RJ, Arnaout OM, Sanusi OR, Kesavabhotla K, Chandler JP: Endoscopic approach to clival chordomas: the Northwestern experience. World Neurosurg 110:e231-e238, 2018

70. Raza SM, Gidley PW, Kupferman ME, Hanna EY, Su SY, DeMonte F: Site-specific considerations in the surgical management of skull base chondrosarcomas. Oper Neurosurg (Hagerstown) 14:611-619, 2018

71. Sakata K, Maeda A, Rikimaru H, Ono T, Koga N, Takeshige $\mathrm{N}$, et al: Advantage of extended craniofacial resection for advanced malignant tumors of the nasal cavity and paranasal sinuses: long-term outcome and surgical management. World Neurosurg 89:240-254, 2016

72. Samii A, Gerganov V, Herold C, Gharabaghi A, Hayashi N, Samii M: Surgical treatment of skull base chondrosarcomas. Neurosurg Rev 32:67-75, 2009

73. Sbaihat A, Bacciu A, Pasanisi E, Sanna M: Skull base chondrosarcomas: surgical treatment and results. Ann Otol Rhinol Laryngol 122:763-770, 2013

74. Shidoh S, Toda M, Kawase T, Nakajima H, Tomita T, Ogawa $\mathrm{K}$, et al: Transoral vs. endoscopic endonasal approach for clival/upper cervical chordoma. Neurol Med Chir (Tokyo) 54 (Suppl 3):991-998, 2014

75. Stapleton AL, Tyler-Kabara EC, Gardner PA, Snyderman CH, Wang EW: Risk factors for cerebrospinal fluid leak in pediatric patients undergoing endoscopic endonasal skull base surgery. Int J Pediatr Otorhinolaryngol 93:163-166, 2017

76. Sughrue ME, Kane AJ, Shangari G, Rutkowski MJ, McDermott MW, Berger MS, et al: The relevance of Simpson Grade I and II resection in modern neurosurgical treatment of World Health Organization Grade I meningiomas. J Neurosurg 113:1029-1035, 2010
77. Tajudeen BA, Arshi A, Suh JD, Palma-Diaz MF, Bergsneider M, Abemayor E, et al: Esthesioneuroblastoma: an update on the UCLA experience, 2002-2013. J Neurol Surg B Skull Base 76:43-49, 2015

78. Tan TSE, Patel L, Gopal-Kothandapani JS, Ehtisham S, Ikazoboh EC, Hayward R, et al: The neuroendocrine sequelae of paediatric craniopharyngioma: a 40 -year meta-data analysis of 185 cases from three UK centres. Eur J Endocrinol 176:359-369, 2017

79. Tawk RG, Binning MJ, Thomas JM, Siddiqui AH, Grand W: Transciliary supraorbital approach (eyebrow approach) for resection of retrochiasmatic craniopharyngiomas: an alternative approach, case series, and literature review. J Neurol Surg A Cent Eur Neurosurg 75:354-364, 2014

80. Terasaka S, Asaoka K, Kobayashi H, Yamaguchi S: Anterior interhemispheric approach for tuberculum sellae meningioma. Neurosurgery 68 (1 Suppl Operative):84-89, 2011

81. Tsang RK, Tsang AC, Lam JW, Ho WK, Leung GK: Longterm results of endoscopic-assisted cranionasal resection for olfactory neuroblastoma-single centre experience of fourteen patients. Clin Otolaryngol 40:274-277, 2015

82. Tsitouras V, Wang S, Dirks P, Drake J, Bouffet E, Hawkins $\mathrm{C}$, et al: Management and outcome of chordomas in the pediatric population: The Hospital for Sick Children experience and review of the literature. J Clin Neurosci 34:169-176, 2016

83. Wang K, Wang L, Tian K, Xiao X, Wu Z, Jia G, et al: Surgical resection of upper-middle clivus chordomas via a modified anterior transpetrous approach. Clin Neurol Neurosurg 130:20-25, 2015

84. Wannemuehler TJ, Rubel KE, Hendricks BK, Ting JY, Payner TD, Shah MV, et al: Outcomes in transcranial microsurgery versus extended endoscopic endonasal approach for primary resection of adult craniopharyngiomas. Neurosurg Focus 41(6):E6, 2016

85. Wessell A, Singh A, Litvack Z: Preservation of olfaction after unilateral endoscopic approach for resection of esthesioneuroblastoma. J Neurol Surg Rep 75:e149-e153, 2014

86. Wilson CB: Adoption of new surgical technology. BMJ 332:112-114, 2006

87. Wilson DA, Duong H, Teo C, Kelly DF: The supraorbital endoscopic approach for tumors. World Neurosurg 82:e243e256, 2014

88. Yano S, Hide T, Shinojima N: Surgical outcomes of endoscopic endonasal skull base surgery of craniopharyngiomas evaluated according to the degree of hypothalamic extension. World Neurosurg 100:288-296, 2017

89. Yokoi H, Kodama S, Kogashiwa Y, Matsumoto Y, Ohkura Y, Nakagawa T, et al: An endoscopic endonasal approach for early-stage olfactory neuroblastoma: an evaluation of 2 cases with minireview of literature. Case Rep Otolaryngol 2015:541026, 2015

90. Younus I, Forbes JA, Ordóñez-Rubiano EG, Avendano-Pradel $\mathrm{R}$, La Corte E, Anand VK, et al: Radiation therapy rather than prior surgery reduces extent of resection during endonasal endoscopic reoperation for craniopharyngioma. Acta Neurochir (Wien) 160:1425-1431, 2018

91. Zaidi HA, Chapple K, Little AS: National treatment trends, complications, and predictors of in-hospital charges for the surgical management of craniopharyngiomas in adults from 2007 to 2011. Neurosurg Focus 37(5):E6, 2014

92. Zanation AM, Snyderman CH, Carrau RL, Gardner PA, Prevedello DM, Kassam AB: Endoscopic endonasal surgery for petrous apex lesions. Laryngoscope 119:19-25, 2009

93. Zhang HK, Sun XC, Hu L, Wang JJ, Wang DH: Endonasal endoscopic resection and radiotherapy in skull base chordomas. J Craniofac Surg 27:e709-e713, 2016

94. Zhang L, Niu K, Zhu K, Xia C, Yan J, Zhao W, et al: Longterm prognostic analysis after endoscopic endonasal surgery 
for olfactory neuroblastoma: a retrospective study of 13 cases. PLoS One 11:e0166046, 2016

95. Zoli M, Milanese L, Bonfatti R, Faustini-Fustini M, Marucci G, Tallini G, et al: Clival chordomas: considerations after 16 years of endoscopic endonasal surgery. J Neurosurg 128:329-338, 2018

96. Zou MX, Lv GH, Zhang QS, Wang SF, Li J, Wang XB: Prognostic factors in skull base chordoma: a systematic literature review and meta-analysis. World Neurosurg 109:307-327, 2018

97. Zygourakis CC, Kaur G, Kunwar S, McDermott MW, Madden M, Oh T, et al: Modern treatment of 84 newly diagnosed craniopharyngiomas. J Clin Neurosci 21:1558-1566, 2014

\section{Disclosures}

The authors report no conflict of interest concerning the materi- als or methods used in this study or the findings specified in this paper.

\section{Author Contributions}

Conception and design: Schwartz, Anand. Acquisition of data: Morgenstern. Analysis and interpretation of data: Schwartz, Morgenstern. Drafting the article: Schwartz, Morgenstern. Critically revising the article: all authors. Reviewed submitted version of manuscript: all authors. Approved the final version of the manuscript on behalf of all authors: Schwartz. Study supervision: Schwartz.

\section{Correspondence}

Theodore H. Schwartz: Weill Cornell Medical College, New York, NY.schwarh@med.cornell.edu. 